\title{
Species delineation and description in Aethaloptera Brauer genus by phallic head (Trichoptera, Hydropsychidae, Macronematinae)
}

\author{
J. OLÁH \\ János Oláh, residence postal address: Tarján u. 28, H-4032 Debrecen, Hungary. \\ E-mail:profolah@gmail.com
}

\begin{abstract}
Taxonomy of the "widely distributed and highly varying species" in the small Aethaloptera genus was questioned long ago. Relying on the macro morphology, detectable by the routine resolution of the stereomicroscope, these species look very similar. However, applying the higher resolution of compound microscope with focusing on profile stability, significant shape divergences have been recognised in the fine structure of the speciation trait that is in the much specialised head structure of the phallic organ. The ancestral prototype of caddisfly genitalia is highly modified in the Hydropsychidae family. The hydropsychid prototype is further organised in the macronematine Aethaloptera genus: the abbreviated primordial genital structures of Hydropsychidae family are retracted into the invaginated tip of the phallotheca with apomorphic organisation of complexity by reduction or simplification, a complexity integrated by incremental subtraction. Examining the fine phenomics of the phallic head we have tripled the species number in this small genus and delineated altogether 12 species. We expect many more species to be collected and distinguished in this neglected genus by the fine structure of this speciation trait. Here we established two new species groups: Aethaloptera dispar new species group and A. meyi new species group and described five new species: Aethaloptera felalla, A. karima, A. malickyi, A. meyi and A. wellsi spp. nov.
\end{abstract}

Keywords. Speciation trait, fine phenomics, incremental subtraction, new Aethaloptera species.

\section{INTRODUCTION}

$\mathrm{T}$ he Aethaloptera Brauer, 1875 genus belongs to the Polymorphanisini tribe of the longhorned hydropsychid Macronematinae subfamily. In its present taxonomic state this is a small genus comprised of four known species. Two species, $A$. dispar Brauer, 1875 and A. maxima Ulmer, 1906 occur in the Afrotropical Region. One species, $A$. evanescent (McLachlan, 1880) is present in the East Palearctic Region. One species, A. sexpunctata (Kolenati, 1859) is distributed both in the Oriental and Australasian Regions. They are usually treated as "widely distributed and highly varying" species: $A$. dispar has been recorded from the entire Afrotropical Region south of the Sahara and A sexpunctata (Barnard, 1980) has even a larger distributional area from India to Australia.

The taxonomy of these "widely distributed and highly varying" species was questioned long ago!
Lestage (1936) doubted that Aethaloptera dispar was the same species throughout Africa. Supporting this view Marlier (1943) stated that there were at least three types of this widely distributed African species present just in Belgian Congo. Kimmins (1962) took an opposite view, suggesting that even Aethaloptera dispar and A. maxima may be only local forms of one widespread species. Malicky (1998) has found unreliable to separate A. gracilis from A. sexpunctata in the Oriental region. Studies on larval morphology indicated that other species are also present in the Afrotropical populations besides A. dispar and A. maxima (Statzner \& Gibon 1984, Ogbogu 2005). In his genus revision Barnard (1980) has concluded the lack of useful diagnostic genitalic characters in the Aethaloptera genus at generic and species level compared to characters found on wings and thorax (Barnard 1980).

We have collected long series of Aethaloptera sexpunctata in several habitats near the locus 
typicus in East India (Orissa) as well as a single male specimen from Vietnam. Superficially, relying on the macro morphology detectable by the routine resolution of the stereomicroscope, the Indian and Vietnamese specimens look very similar. However, applying the higher resolution of compound microscope and focusing on profile stability we have found significant shape divergences in the fine structure of the speciation trait that is in the much specialised head structure of the phallic organ. This discovery inspired us to realise a systematic survey on all of the available Aethaloptera materials. In this paper we have tripled the species number in this genus and delineated 12 species based upon our very limited material. We suppose that many more species are waiting to be collected and distinguished by specialised systematic collecting efforts and by detecting the divergences in the fine structure of the speciation traits.

\section{Fine structure of the speciation trait}

Fine phenomics is not just a more powerful procedure of magnification applying compound microscope of much higher resolution instead of routine stereomicroscopy. It is right that applying higher resolution to visualise, discern and draw the fine structures of phenomics significantly improves our capacity to find the adaptive early shape divergences of initial splits in reproductive barrier buildings. But fine phenomics could be efficiently applied with lower resolution of stereomicroscopy if our focus is properly and adequately directed to the subtle and stable shape divergences, like the lateral profile of the phallic head detectable also at lower magnification in Aethaloptera. In the routine practice of gross phenomics these small divergences are usually neglected and interpreted as variations and not as building of reproductive barriers in early divergences. Stability of "small divergences" appears convincing and very demonstrative if we examine population samples with several specimens and put together in matrices as we have realised here at species with more specimens.

In the Aethaloptera genus the gross morphology of genitalia, as well as the wing venation have low diversity and wide range of variation. For instance the fork 4 on forewing, whether sessile or stalked, is highly variable even inside populations. This is the common nature of neutral traits, directly exposed to random impacts of effective population size, genetic drift and recombination. Contrary, the diversity of the phallic head is high and these fine structure divergences are very stable, not variable. These diverse and stable character states are the direct evidences of contemporary, recent past adaptive divergences. The stability of these adaptive non-neutral speciation traits is organised and maintained by several integrative and protective mechanisms (Oláh \& Oláh, 2017). In this genus the phallic head with diverse and stable shape divergences represents the adaptive, non-neutral speciation trait organised by integration during the sexual processes of speciation and resulted in reproductive barrier building. The phallic head of Aethaloptera is characterised by much specialised apomorphic state of abbreviated and retracted terminal structures, compared to the plesiomorphic state of the endotheca present in the ancestral arctopsychine subfamily, in ancestral macronematine genera, like Leptonema and in most genera of hydropsychine subfamily. In the genera of Hydropsychinae subfamily an inverted endophallus or, as argued by Korecki (2006), an inverted phallicata (aedeagus) is present in the form of internal atrium inside the phallotheca. But we have to remind that all extant species are a mix of ancestral and derived characteristics and not the extant organism is ancestral/primitive/branched early or derived/young/branched off last (Omland et al. 2008).

The ancestral prototype of the caddisfly phallus has a well sclerotized phallobase (or phallotheca), an apical tubular aedeagus (sclerous phallicata) and they are connected and mobilised by a membranous flexible endotheca supplied with endothecal processes (parameres). This tripartite tubular telescopic structure is traversed through by the sperm duct, the slender tubular ductus ejaculatoricus and discharges into the endophallus through the gonopore. The endophallus or directly the sperm duct discharges into the vaginal 
chamber through the pore of the phallotreme operated or regulated by a pair of phallotemmal sclerites.

Compared to this ancestral prototype, the phallic structure of the Hydropsychidae is highly modified. The phallotheca is elongated and the basic telescopic architecture of endotheca, aedeagus and endothecal processes is restructured. They have been abbreviated or highly reduced and moved in terminal position to the very distal end of the phallotheca. In spite of these modifications these miniaturized and concentrated structures cover the entire range of reproductive functions, intromittent, titillation, stimulation and ejaculation. In hydropschines the prototypic endotheca, paramere and aedeagus are simplified into: (1) traces of the membranous endotheca; (2) various membranous and sclerotized endothecal processes or lobes (reduced parameres?); (3) variously developed phallotremal sclerites (abbreviated aedeagus?).

In most macronematine genera and in the hydropsychine Hydropsyche angustipennis and $H$. asiatica species groups these abbreviated structures are withdrawn from the free distal position and are retracted inside the intact or cleft tip of the tubular phallotheca. This condition seems to be the most derived state in the organisation of the phallic structure among the hydropsychids. This is a form of specialization by simplification that could be an inherent complexity increase (Oláh $e t$ al. 2017). The phallic organ of the macronematine Aethaloptera genus is the result of similar apomorphic organisation of complexity by reduction, simplification or specialization. Complexity could arise, not only by incremental addition but by incremental subtraction. Early plesiomorphic complexity is followed by later reduction (McShea \& Hordijk 2013) even without evolutionary zeroforce law (McShea \& Brandon 2010).

The primordial plesiomorphic phallic organ of the caddisfly prototype is simplified in the Aethaloptera genus into the simple tube of phallotheca with abbreviated and retracted terminal structures. The sperm duct enters the phallotheca and its discharge locality is almost indiscernible. The pre- sence of variously widened atrium-like endophallic structure is questionable. Especially its dorsum frequently appears diffuse. Its ventrum is discernible due to the presence of a more discernible structure similar to the pigmented sclerous band located alongside in hydropsychine genera. The endophallus or the ejaculatory duct seems to empty through the apical opening of the phallotreme.

Fine structure of the abbreviated and invaginated primordial components. The sperm discharging opening, that is the phallotreme is flanked by (1) a pair of variously shaped small phallotremal sclerites. These tiny phallotremal sclerites are accompanied and superimposed (sheltered, mounted or flanked) by (2) a larger pair of endothecal sclerites. This double layered complex is retracted into the terminal tip of the phallothecal tube and positioned usually in the larger ventral half of the tube terminal, but can move middle and dorsad, its position can be influenced by natural function or preparation. Its position is detectable by its darker pigmentation and by observing the position of the ejaculatory duct leading to its terminal opening that is to the phallotreme. The variously membranous and discernible ejaculatory duct can be detectable by variously discernible band located along its ventrum. This band leads to the phallotremal sclerites and operates their opening and closing movements. The head of the sclerous band widened into (3) variously shaped and detectable small plate or rim with articulation into the pair of phallotremal sclerites. The smaller dorsal part of the tube tip gives some place to remnant traces of (4) vestigial endothecal structures, if present.

Fine structures of the invaginated phallothecal tip. The phallic head has specific lateral (5), ventral (6) and dorsal (7) profiles. The invaginated tip of the phallothecal tube has produced the variously patterned and enforced (8) aperture rim or lips. The depth of invagination that is the entrance atrium (9) determines the extension and the shape of apical cavity giving room and partially occupied by the abbreviated and invaginated primordial components. The magnitude and position of the apical opening of the entrance atrium de- 
termines, together with the rim configuration, the shape and location of the (10) aperture slit.

\section{MATERIAL AND METHODS}

This genus revision is based on the fine phenomics of the phallic head. The material available for this study was collected by the author and by colleagues as indicated at the examined materials. Unfortunately, the extent and the comprehensiveness of this study was highly limited by the restricted sampling effort like to any other contemporary taxonomic revision struggled to create in the present suppressed status of taxonomy.

Observational and drawings limits. The ten variously shaped and sclerotized tiny fine structures composing the adaptive speciation trait in species of the Aethaloptera genus may have high diagnostic value. This is again an example of infinite empirical potential not utilised yet in taxonomy. However, there are still limits to examine them in the routine practice of the present day taxonomists. Taxonomy needs a move toward new high-tech and high-throughput procedures (Oláh et al. 2015). A high quality stereomicroscope produces a three-dimensional visualization of the genital structures with great working distance and sufficient depth of field, but with limited magnification. Contrary, the higher magnification potential of the compound microscope may help to detect and understand fine structures of the genitalia, but with small depth of field. The visibility or even the reliable discernibility of the abbreviated and invaginated primordial structures in the Aethaloptera is rather reduced even with a compound microscope due to specific inherent structural modalities and methodological constraints. These structures are: (1) tiny; (2) variously pigmented; (3) frequently irregularly shaped and very complex; (4) retracted inside the thick distal end of the phallothecal tube; (5) covered by the variously pigmented tip of the phallothecal tube; (6) covering each other's; they may have (7) interconnections, amalgamations or fusions of the four components; high sensitivity to the (8) viewing angles and (9) dislocated or even distorted by copulatory natural functions or (10) during pre- servation and preparation. Owing to these limitations we do not rely systematically upon all of these structures in the present species delineation of the Aethaloptera genus. We distinguish incipient sibling species mostly by the lateral profile of the phallic head, by the extension of the concavity, that is the entrance atrium and by the shape and location of the aperture slit. The shape of the phallotremal sclerite and endothecal process complexes is not exactly drawn, just outlined, due to the above listed inherent conditions.

Depositories. Australian National Insect Collection, Canberra, Australia (ANIC)

British Museum Natural History, London, England (BMNH)

Malicky Private Collection, Lunz-am-See, Austria (MPC)

Museum of Comparative Zoology, Harvard (MCZ)

Museum for Natural History of the Humbolt University of Berlin, Germany (ZMB).

Oláh Private Collection, Debrecen, Hungary, under national protection by the Hungarian Natural History Museum, Budapest (OPC).

Swedish Museum of Natural History, Stockholm, Sweden (SMNH)

\section{TAXONOMY}

\section{Aethaloptera Brauer, 1875}

Aethaloptera Brauer, 1875: 71. Type species: Aethaloptera dispar Brauer, by monotypy.

Chloropsyche McLachlan, 1880: 69. Type species Chloropsyche evanescens McLachlan, by monotypy. Synonymized by Kimmins 1962: 96.

Primerenca Navas, 1915: 181. Type species Primerenca maesi Navas, by original designation and monotypy. Synonymized by Lestage 1919: 293.

Paraethaloptera Martynov, 1935: 193. Type species Paraethaloptera gracilis Martynov, by original designation and monotypy. Provisionally synonymized by Kimmins 1962: 96; formally synonymized by Barnard 1980: 68.

The Aethaloptera genus is a member of the Polymophanisini tribe together with the Polymorphanisus, Oestopsyche and Synoesropsis genera in the long-horned Macronematinae subfamily of the Hydropsychidae family. This tribe is composed of a very discrete group of genera having obvious 
diagnostic character in the absence of maxillary and labial palps. Amphipsyche having an overall similarity to the Polymorphanisini tribe, but has mouthparts present, sometimes in a reduced state. Whether a primary reduction or a late reintegration have resulted the presence of maxillary and labial palps in the Amphipsyche genus is still unresolved, but reminds us again that taxa are a mix of ancestral and derived characteristics and only character state is ancestral or derived. As a result we have to rely mostly on the generality and locality principles in character ranking and distinguish

(1) Macronematinae subfamily by the elongated antennae;

(2) Polymorphanisini tribe by the vestigial mouthparts;

(3) Aethaloptera genus by the false discal cell;

(4) Aethaloptera species groups by the position of inverted atrium and aperture slit.

(5) Species by the shape of phallic head, inverted atrium and aperture slit.

Based on the position of the inverted entrance atrium and aperture slit the Aethaloptera genus has two species groups: Aethaloptera dispar new species group with apical aperture slit and Aethaloptera meyi new species group with dorsal aperture slit.

\section{Aethaloptera dispar new species group}

The aperture rim of the invaginated distal end of the phallotheca, the entrance atrium and its apical opening with the rim configuration that is the aperture slit is positioned apicad or near apicad. This is the probable ancestral character state in the genus based upon the generality locality and parsimony principles. This state is more general, its representatives are distributed both on the Afrotropical and Oriental and Australasian regions and the organisation of inversion is simpler; compared to the dorsal position of the entrance atrium at the A. meyi species group with less general character state, limited geographical distribution and with more complex organisation of invagination procedures.

\section{Afrotropical species}

Aethaloptera dispar Brauer, 1875

(Figures 1-5)

Aethaloptera dispar Brauer, 1875: 72. "Von Herrn Dr. F. Steindachner am Senegal (bei Taoué) im November massenhaft gefunden."

Aethaloptera dispar Brauer, 1875. Barnard 1980: 68. Designation of lectotype male, Senegal, near Taoué, XI. 1869 (Steindachner) (NM, Vienna).

Material examined. Congo, Brazzaville, OR STOM park, 22. XI.-24. XII. 1963, light trap, leg. J. Balogh, A. Zicsi \& S. Endrödy-Younga, (4 males, OPC).

Diagnosis. The four male specimens examined from Congo have the shape of the phallic head almost identical to the designated lectotype from Senegal (Barnard 1980), including the size and position of the aperture slit, that is the opening delineated by the phallothecal apical lips. The lateral profile of the phallic head slightly elongated upward obliquely and with an angular apicoventral corner, not short and rounded like the phallic head of A. maxima. The invaginated entrance atrium is less developed and differently patterned compared to A. maxima.

\section{Aethaloptera maesi (Navas, 1915) Stat. restit.}

\section{(Figures 6-8)}

Primerenca maesi Navas, 1915: 182. Holotype male, not females as stated by Barnard (1980).

Primerenca marina Navas, 1916: 242. Unjustified emendation!

Aethaloptera dispar Brauer, 1875. Lestage 1919: 293: transferred to Aethaloptera genus and synonymized with Aethaloptera dispar Brauer.

Aethaloptera maesi (Navas, 1915: 182). Marlier questioned synonymy (1943) and listed among the three African Aethaloptera species (1962) without formal reinstatement. Here we reinstate its species status. Stat. restit. 


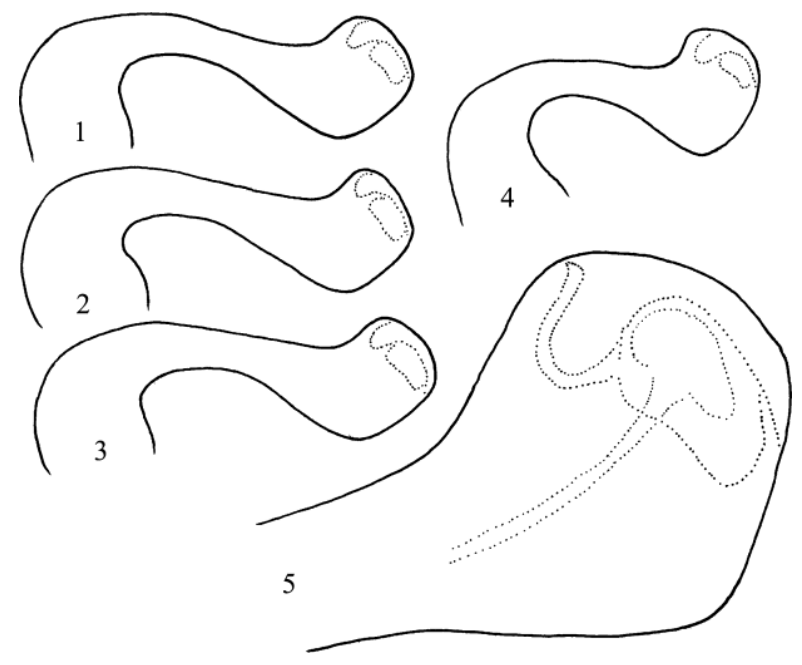

Figures 1-5. Aethaloptera dispar Brauer, 1875. 1-4 = stereomicroscope lateral profile of the phallic organ, $5=$ compound microscope lateral profile of the phallic head with internal dotted contours of entrance atrium and phallotremalendothecal sclerite complex.

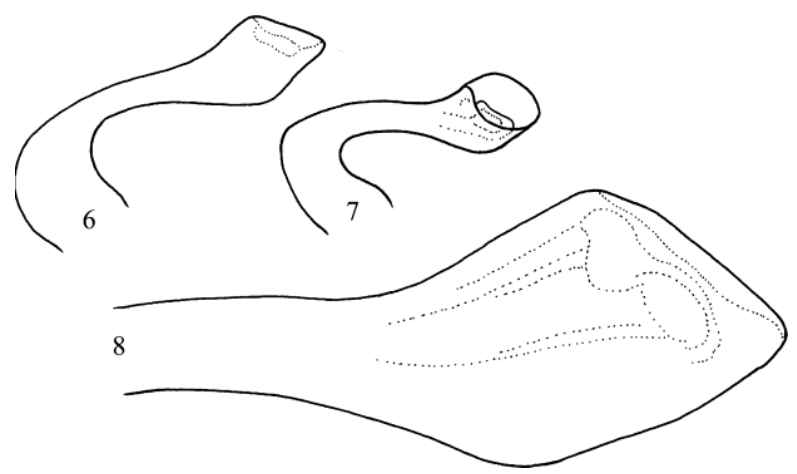

Figures 6-8. Aethaloptera maesi (Navas, 1915). 6 = stereomicroscope lateral profile of the phallic organ, $7=$ stereomicroscope laterocaudal profile of the phallic organ, $8=\mathrm{com}-$ pound microscope lateral profile of the phallic head with internal dotted contours of entrance atrium and phallotremalendothecal sclerite complex.

Material examined. Congo, Brazzaville, OR STOM park, XI.-24. XII. 1963, light trap, leg. J. Balogh, A. Zicsi \& S. Endrödy-Younga, (1 male, $\mathrm{OPC})$.

Diagnosis. Barnard (1934) accepted Lestage's synonymy of $P$. maesi with $A$. dispar and the lateral hook on segment $\mathrm{X}$ was explained by deformation due to the unequal chitinization of the lobes. Contrary, Marlier (1943) interpreting different forms of Aethaloptera dispar collected in Congo suggested that Aethaloptera maesi (Navas) was a valid species and later he has listed among the three African species however, without formal reinstatement (Marlier 1962). A single male specimen was found in the light trap operated in Brazzaville by Hungarian collectors. Brown spot marking, sessile Fork IV and the outstanding hook formation on the lateral lobes of segment $\mathrm{X}$ correspond exactly with Navas's description and drawing.

This is a distinctly diverged species clearly detectable even by the neutral trait of the lateral lobes on segment $\mathrm{X}$. Moreover, the speciation trait of the phallic head has diverged very significantly from the phallic head of $A$. dispar. The lateral profile of the head is almost funnelled and truncated apicad, not obliquely upward directed. The aperture slit very wide almost circular, not narrow as a result the entrance atrium is very open and shallow. The abbreviated and invaginated phallotremal sclerite and endothecal process complex moved dorsad in middle position, not located in ventral half position as in $A$. dispar and $A$. maxima.

\section{Aethaloptera maxima Ulmer, 1906}

(Figures 9-15)

Aethaloptera maxima Ulmer, 1906: 62. "1ðิ, bez. Bothaville, Orange-Freistaat, 25. III. 1899, Dr. H. Brauns leg., vend. 9. X. 1899, Hamburger Museum.”

Aethaloptera maxima Ulmer, 1906. Barnard 1980: 72, "Neotype ô, South Africa:Waterval River, National Road between Standerton and Greylingstad, 12. I. 1959 (ZM, Hamburg), here designated (examined)."

Material examined. Namibia, Orange River, Vioolsdrift, 12. II. 1994, leg. Koch (1 male, 1 female; OPC). Kavango, Popa Falls, 26. II.-2. III. 1992, leg. W. Mey (1 male, 9 females, ZMB). Orange, Nordvever, 13. IIII. 2003, leg. W. Mey (1 female, ZMB). Kavango, Popa Falls, 10. III. 2009, leg. W. Mey (1 female, ZMB). $7 \mathrm{~km} \mathrm{E} \mathrm{of}$ Rundu, $17^{\circ} 56 \mathrm{~S} 19^{\circ} 49$, E 18.-19. VI. 1993, leg. B. + M. Uhlig (1 male, ZMB). South Africa, Vaal River at Frankfort, 13. III. 1965, leg. F. M. Chutter (Albany Museum, MISC 218, 1 male, 1 female; OPC). Kunene River at Palm Grove Camp, 17. XI. 1997, leg. F.M. Chutter (Albany Museum, KUN 66S, 2 males, AM; 2 males, OPC). 


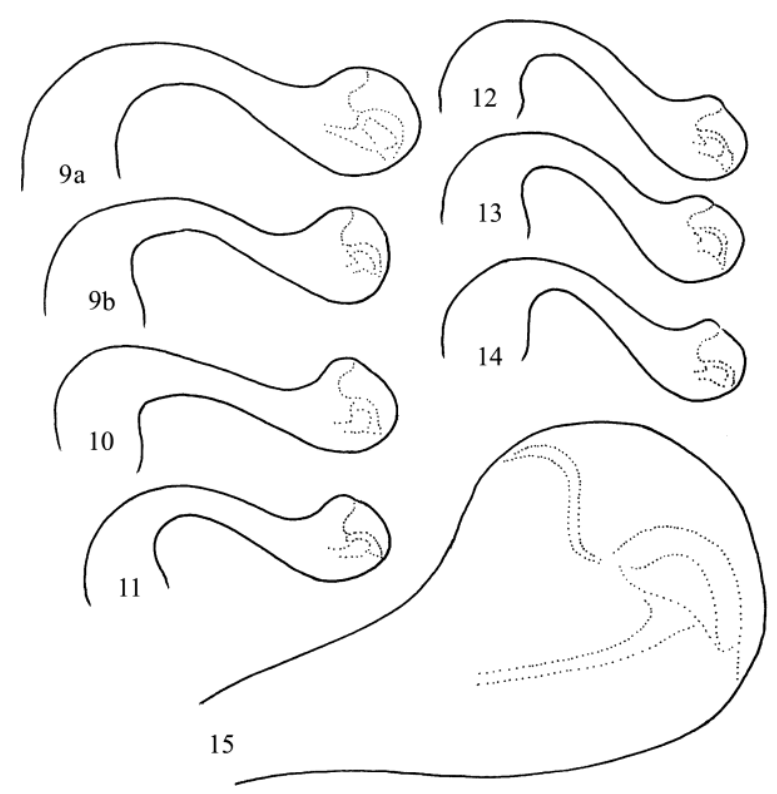

Figures 8-15. Aethaloptera maxima Ulmer, 1906. 8 = stereomicroscope lateral profile of the phallic organ, Vaal River, South Africa, 9a, b = stereomicroscope lateral profile of the phallic organ, Orange River, South Africa, $10=$ stereomicroscope lateral profile of the phallic organ, Rundu, Namibia, 11-14 = stereomicroscope lateral profile of the phallic organ, Kunene River, South Africa, 15 = compound microscope lateral profile of the phallic head with internal dotted contours of entrance atrium and phallotremal-endothecal sclerite complex.

Diagnosis. All the examined 6 populations exhibited very high shape stability of the phallic head that is the speciation trait including the size and position of the aperture slit, that is the opening delineated by the phallothecal apical lips. The lateral profile of the phallic head short and rounded; not elongated upward obliquely and not with an angular apicoventral corner, like the phallic head at $A$. dispar. The invaginated entrance atrium more developed and differently patterned compared to A. dispar.

\section{Oriental species}

\section{Aethaloptera dyakana Banks, 1920 Stat. restit.}

Aethaloptera dyakana Banks, 1920: 354. Holotype female, Borneo, Duson Timoc (Grabowsky). Type deposited in MCZ: type no. 10885.

Aethaloptera sexpunctata Kolenati, 1859. Ulmer 1951: 194, synonymized with A. sexpunctata.

Aethaloptera sexpunctata Kolenati, 1859. Barnard 1980: 75 , listed as synonym.
Remarks. Applying the locality principle, A. dyakana Banks described from a single female collected in Borneo must be an independent species isolated and derived directly or indirectly from A. sexpunctata Kolenati. Here we reinstate its species status. Stat. restit.

\section{Aethaloptera evanescens (McLachlan, 1880)}

\section{(Figures 16-17)}

Chloropsyche evanescent McLachlan, 1880: 69-70. Russia, Amurland (Christoph, 2 males). Type deposited in BMNH.

Chloropsyche evanescent McLachlan, 1880. Kimmins 1957: 105, Lectotype male. Amurland, B.M. 1938674. "The second male mentioned by McLachlan is no longer in his collection."

Aethaloptera rossica Martynov, 1910: 385. Syntypes males, females, Rossia: Ussurian Amurland and S. Siberia to R. Ob (?ZI, Leningrad). Barnard 1980: 74, synonymized with A. evanescens.

Material examined. Russia, Khabarovsk Terr., Slavyanka at Amur, light trap, 17. VI. 1994, light trap, leg. P. Lindskog \& B. Viklund (2 males, $\mathrm{SMNH}$; 1 male, OPC).

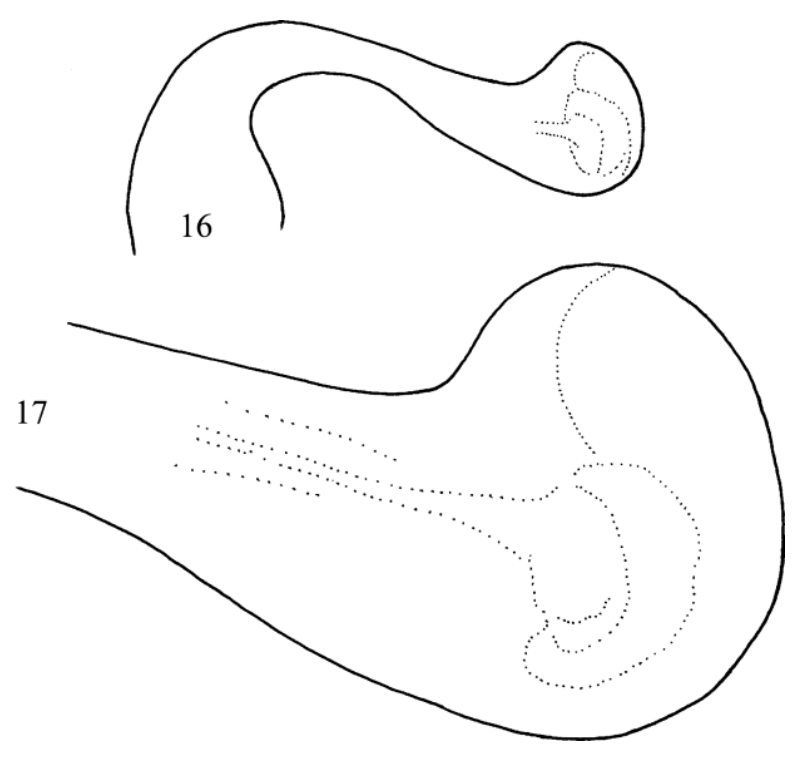

Figures 16-17. Aethaloptera evanescens (McLachlan, 1880).

$16=$ stereomicroscope lateral profile of the phallic organ, 17 = compound microscope lateral profile of the phallic head with internal dotted contours of entrance atrium and phallotremal-endothecal sclerite complex. 
Diagnosis. An East-Palearctic species with great resemblance to $A$. sexpunctata, but differs by the straight dorsum of the phallotheca, not as concave subapicad, by the lower phallic head and the larger entrance atrium as well as the phallotremal sclerite and endothecal process complex located more ventrad.

\section{Aethaloptera malickyi sp. nov.}

(Figures 18-24)

Material examined. Holotype. Vietnam, Bac Thai Province, Thain Guyen, Song Cau River, 23. V. 1987, light leg. G. Oláh (1 male, OPC). Allotype. Vietnam, Nam Cat Tien, $11^{\circ} 26^{\prime} \mathrm{N} 107^{\circ}$ 26'E, 200 m, 17.-25. VI. 1995, leg. H. Malicky (1 female, MPC) Paratypes. Same as allotype (1 male, MPC; 1 female, MPC; 2 females, OPC).
Diagnosis. Vietnamese species collected both from South Vietnam and from North Vietnam. The phallotheca of A. malickyi is without pronounced dorsal subapical concavity in lateral view. The phallic head is almost regular circular in both populations, not elongated dorsally like at A. sexpunctata or apically like at A. punctata. Entrance atrium is larger than at $A$. sexpunctata and the phallotremal sclerite and endothecal process complex located more ventrad. In females the sclerotized apical pair of setose lobes on sternite VIII is short and touching middle.

Etymology. We dedicate this new species to Hans Malicky who has collected the second male to remember his productive research activity on caddis flies.
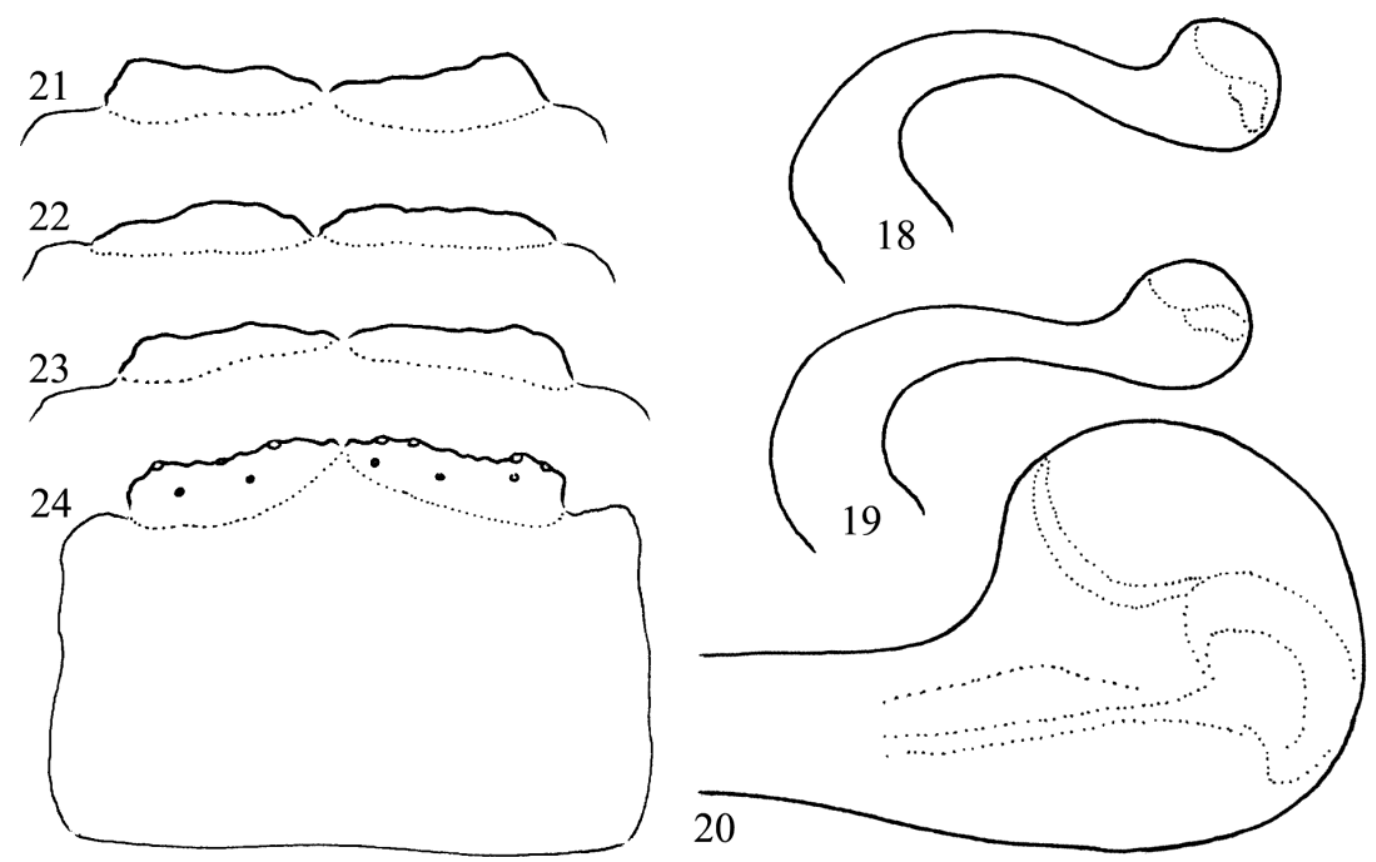

Figures 18-24. Aethaloptera malickyi sp. nov. $18=$ stereomicroscope lateral profile of the phallic organ, North Vietnam, $19=$ stereomicroscope lateral profile of the phallic organ, South Vietnam, $20=$ compound microscope lateral profile of the phallic head with internal dotted contours of entrance atrium and phallotremal-endothecal sclerite complex, $21-24=$ pair of setose sclerite on the apical margin of female sternite VIII in ventral view. 


\section{Aethaloptera punctata (Banks), 1920}

(Figures 25-30)

Paraethaloptera punctata Banks, 1938: 232. Holotype female, West Malaysia, Negri Sembilan: Port Dickson, Jan. 10; and Selangor, Kuala Lumpur 4 to 16 April, Febr. 8, (Pendlebury).

Aethaloptera punctata Banks, 1938. Kimmins 1962: 96, transferred to Aethaloptera.

Aethaloptera sexpunctata (Kolenati, 1859). Barnard, 1980: 75, erroneously synonymized with $A$. punctata.

Material examined. Malaysia, Johor: Endau Rompin, MNS Natural Education Research Center Base Camp, $02^{\circ} 31.95 \mathrm{~N} 103^{\circ} 21.97 \mathrm{E}, 0-150 \mathrm{~m}$, 20. III. 1999, leg. T. Trilar \& K. Prosenc, (1 male, MPC). Indonesia, N-Sumatra, Bukit Maratya, Fluß Bahapal, 3º0N 99 ${ }^{\circ} 14 \mathrm{E}, 200 \mathrm{~m}, 12$. II. 1991, leg. H. Malicky (1 female, MPC). Sumatra, Kebun Sei Kopas, $2^{\circ} 49 \mathrm{~N} 99^{\circ} 18 \mathrm{E}, 200 \mathrm{~m}, 16$. XI. 1997, leg. Diehl (1 female, MPC). Sumatra, Huta padang, Sungai Sila, $2^{\circ} 47 \mathrm{~N} 99^{\circ} 14 \mathrm{E}, 200 \mathrm{~m}, 30$. X. 1992, leg. Diehl (2 females, OPC).

Diagnosis. Diverged probably from A. sexpunctata, but differs by the phallotheca, not as concave subapicad, by the phallic head elongated apically, not dorsally, by the much larger entrance atrium as well as the phallotremal sclerite and endothecal process complex located middle. In the probable females collected in nearby regions in Sumatra the sclerotized apical pair of setose lobes on sternite VIII is very short and not touching middle.

\section{Aethaloptera sexpunctata (Kolenati, 1859)}

(Figures 31-64)

Setodes sexpunctata Kolenati, 1859: 266. Holotype male, India (Hügel) (NM, Vienna).

Aethaloptera sexpunctata (Kolenati, 1859). Ulmer 1907: 19, "Ich sah nur die beiden Typen ( Kolenati's, Ost-Indien".

Paraethaloptera gracilis Martynov, 1935: 193-194, "4ㅇ․ Sanjai River, Chakradharpur, Chota Nagpur. 8-10. II. 18. N. Annandale and F. H. Gravely."

Aethaloptera gracilis Martynov, 1935. Barnard 1980: 68: Paraethaloptera synonymised with Aethaloptera.

Aethaloptera gracilis Martynov, 1935. Malicky 1998: 400, probable synonym of $A$. sexpunctata.
Material examined. India, Orissa State, Bhubaneshwar, Daya River, 31. III. 1985, light leg. J. Oláh (36 males, 2 females; OPC). Orissa State, Bhubaneshwar, Dhauli, swamp area, 20-28. II. 1987, light leg. J. Oláh (47 males, 1 female; OPC). Patna, leg. W. Graf (2 females, MPC; 1 female, OPC). Delhi, Beran, 240 m, 20-23, VIII. 1981, leg. H. Malicky (2 females, MPC; 1 female, OPC). Laos, Central, $70 \mathrm{~km}$ NE Vientiane, Ban Phabat env., 150 m, 27. IV.-1. V. 1997, leg. C. Holzschuh (3 females, MPC; 2 females OPC). Myanmar, Bagan, 2. VII. 2007, leg. E. Heis, (2 males, MPC; 1 male, OPC). Bagan, 16. II. 2003, leg. E. Heis, (4 males, MPC; 6 males, OPC). Thailand, Mae Ping $2 \mathrm{~km} \mathrm{~S}$ von Chiangmai, 25. XI. 1997, leg. P. Chaibu (3 males, MPC; 1 male, OPC). Thailand, Ping bei Lampun, 22. XII. 1989, leg. H. Malicky (3 males, MPC; 2 males, OPC).

Diagnosis. An Oriental species detected from India to Laos. Specimens collected from Vietnam, Malaysia, Borneo and Australia and determined as A. sexpunctata represent independent species. The phallotheca of $A$. sexpunctata is characterized by very pronounced dorsal subapical concavity and dorsally elongated phallic head. Entrance atrium small and the phallotremal sclerite and endothecal process complex located dorsad. In females the sclerotized apical pair of setose lobes on sternite VIII is short mesad and longer laterad and not touching middle.

\section{Australasian species}

\section{Aethaloptera wellsi sp. nov.}

(Figures 65-66)

Material examined. Holotype. Australia, Queensland, Palmerston National Park, Henrietta Ck. Camp, 17³6'S, 145²46'E, 6. IV. 1997, leg. P. Zwick (1 female, MPC). Paratypes. Australia, Queensland, 20 miles W of Tully, 20. IV. 1964, leg. I. F. Common \& M. S. Upton (8 females, ANIC, 2 females, MPC, 2 females OPC).

Diagnosis. An Australian species collected in Queensland. Only females have been collected. Among the dark spots on forewing pattern the 


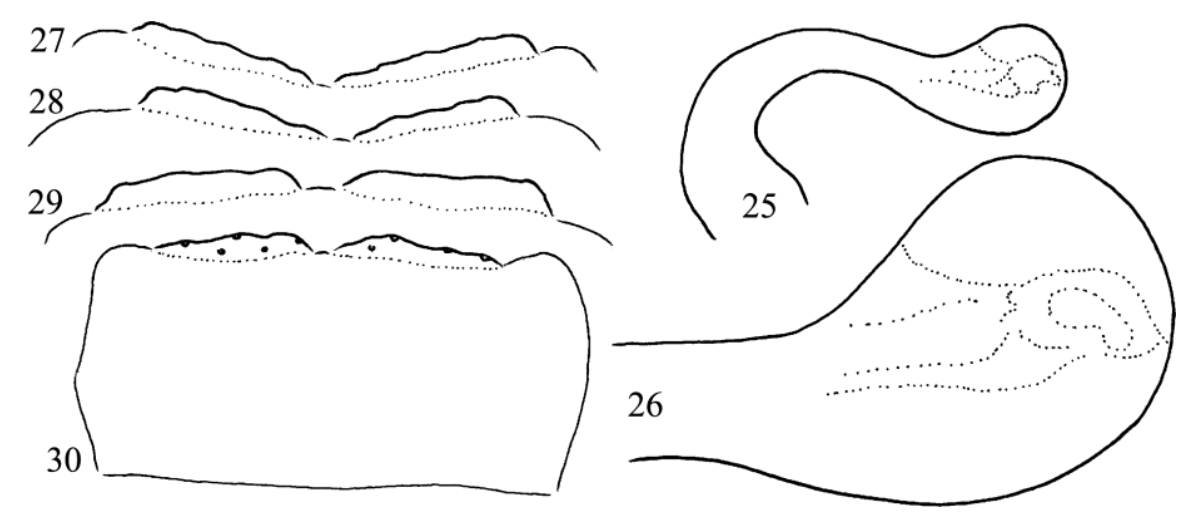

Figures 25-30. Aethaloptera punctata (Banks, 1920). $25=$ stereomicroscope lateral profile of the phallic organ, $26=$ compound microscope lateral profile of the phallic head with internal dotted contours of entrance atrium and phallotremal-endothecal sclerite complex, 27-30 = pair of setose sclerite on the apical margin of female sternite VIII in ventral view.

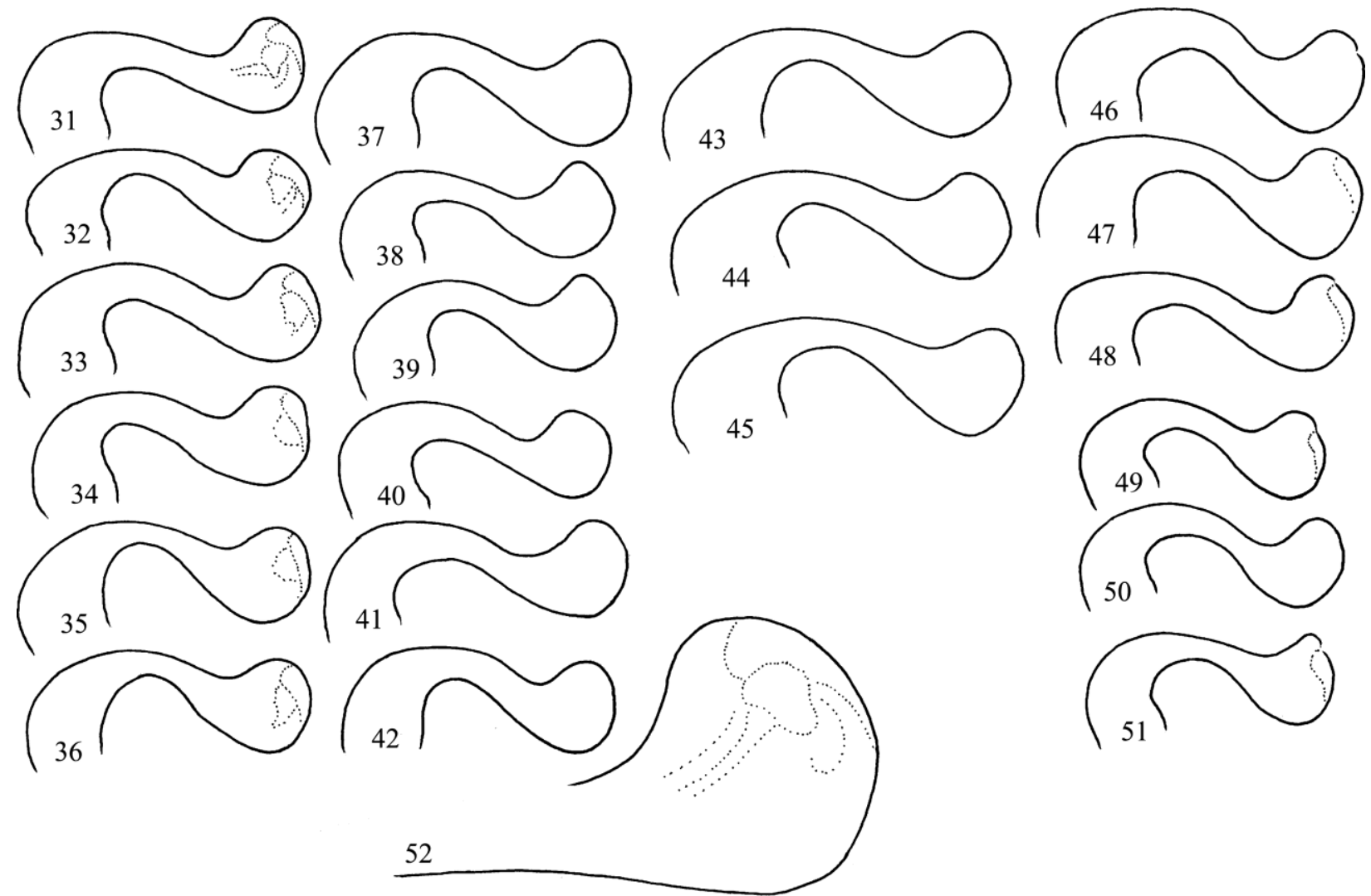

Figures 31-52. Aethaloptera sexpunctata (Kolenati, 1859). 31-36 = stereomicroscope lateral profile of the phallic organ, Dhauli, Orissa, India, 37-42 = stereomicroscope lateral profile of the phallic organ, Daya River, Orissa, India, 43-45=stereomicroscope lateral profile of the phallic organ, Patna, India, 46-48=stereomicroscope lateral profile of the phallic organ, Myanmar, 49-51 = stereomicroscope lateral profile of the phallic organ, Thailand, $52=$ compound microscope lateral profile of the phallic head with internal dotted contours of entrance atrium and phallotremal-endothecal sclerite complex. 

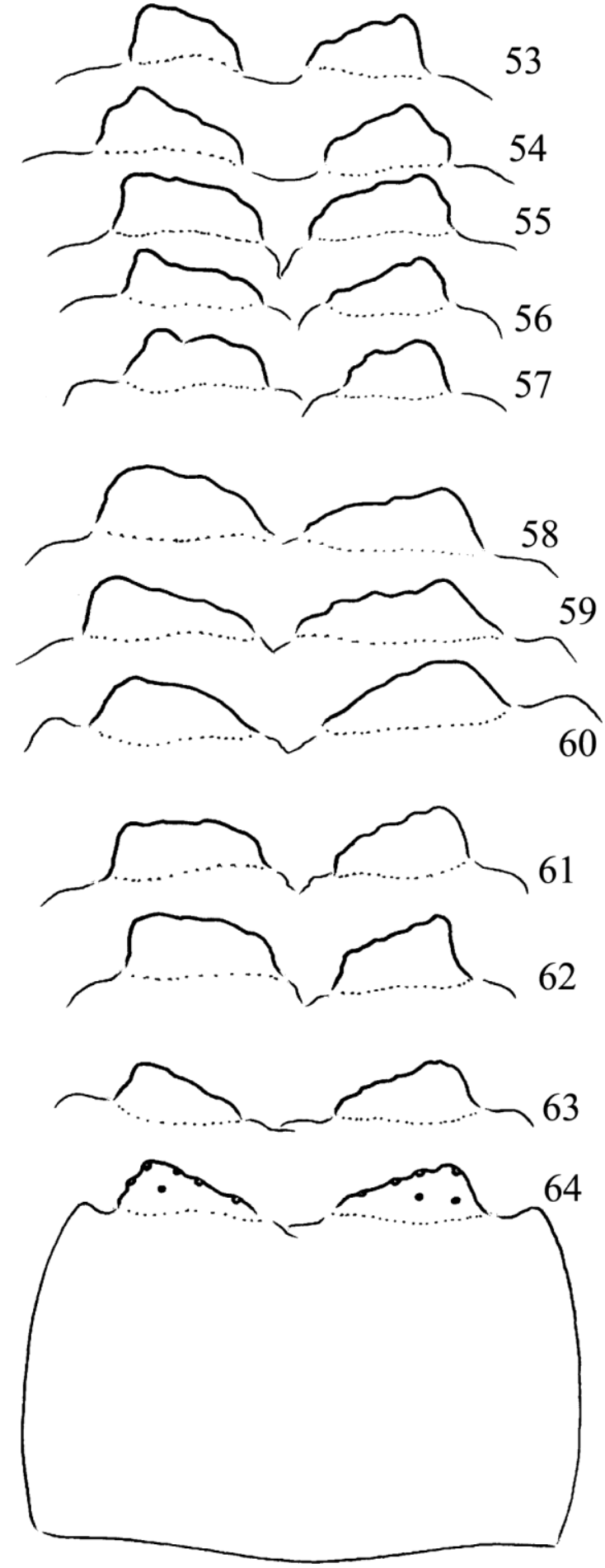

Figures 53-64. Aethaloptera sexpunctata (Kolenati, 1859). Pair of setose sclerite on the apical margin of female sternite VIII in ventral view. 53-57 = Laos, 58-60 = Delhi, India, 61-62 = Daya River, Orissa, India, 63-64 = Dhauli, Orissa, India. spot on crossvein $\mathrm{cu}$ is very pronounced. The pair of spots on forewings is very dominating and characteristic also in resting position. This spot is much less developed at all the know Athaloptera species. The sclerotized apical pair of setose lobes on sternite VIII is long both mesad and laterad and not touching middle, located far from each other.

Etymology. We dedicate this new species to Alice Wells to remember her devoted and productive research activity on the Australian caddisflies.

\section{Aethaloptera meyi new species group}

The aperture rim of the invaginated distal end of the phallotheca, the entrance atrium and its apical opening with the rim configuration that is the aperture slit is moved anterad, positioned dorsad. This species group represents the probable derived character state in the genus based upon the generality, locality and parsimony principles. Its representatives are known only in the Afrotropical faunal region.

\section{Aethaloptera felalla sp. nov.}

(Figures 67-68)

Material examined. Holotype. Congo, Brazzaville, ORSTOM park, 22. XI.-24. XII. 1963, light trap, leg. J. Balogh, A. Zicsi \& S. Endrődy-Younga, (1 male, OPC). Paratypes. Same as of holotype (16 males, OPC).

Diagnosis. This new species has the pointed triangular lateral lobes of segment $\mathrm{X}$ both in dorsal and lateral view. The aperture rim of the invaginated distal end of the phallotheca, the entrance atrium and its apical opening with the rim configuration that is the aperture slit is moved anterad, positioned dorsad supplied with an upward directed and elongated anterior rim larger than at A. karima sp. nov. The enlarged phallic head is elongated in lateral view and broad, slightly bilobed in ventral view. The phallotremal sclerite and endothecal process complex is located posteroventrad. 


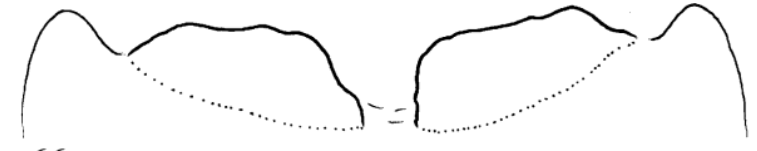

66

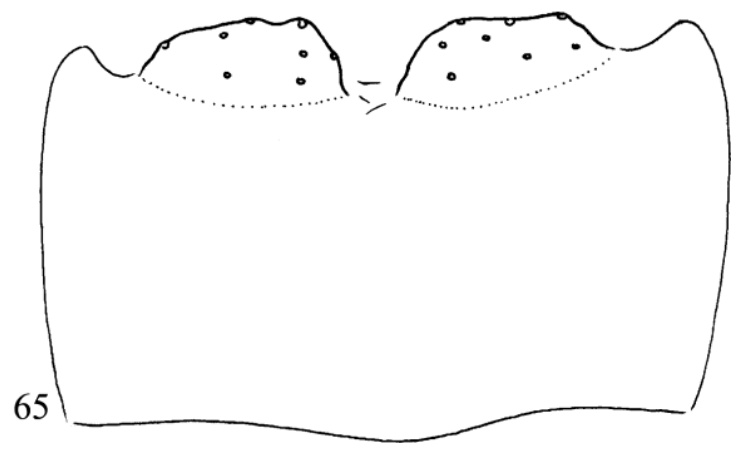

Figurers 65-66. Aethaloptera wellsi sp. nov. Pair of setose sclerite on the apical margin of female sternite VIII in ventral view. $65=$ holotype, $66=$ paratype.

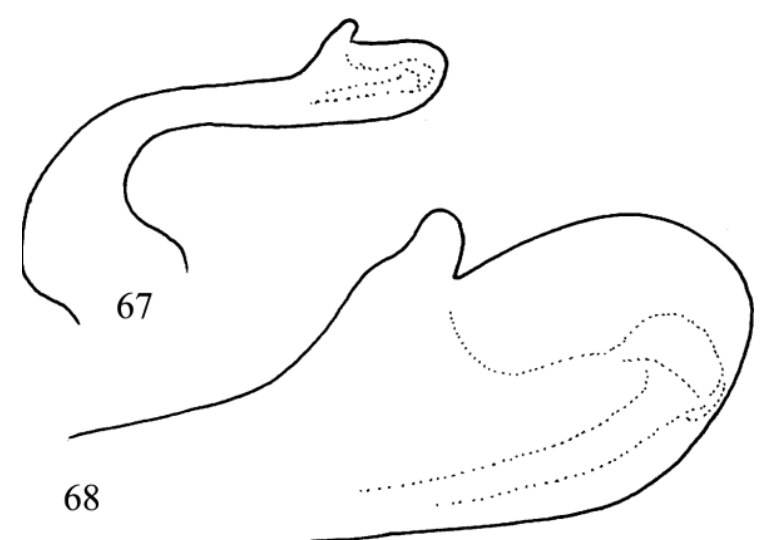

Figures 67-68. Aethaloptera felalla sp. nov. $67=$ stereomicroscope lateral profile of the phallic organ, $68=$ compound microscope lateral profile of the phallic head with internal dotted contours of entrance atrium and phallotremalendothecal sclerite complex.

Etymology. felalla, from ,feláll" upward directed in Hungarian, refers to the enlarged and obliquely upward directed posteromesal lobe of the enforced rim of the aperture slit.

\section{Aethaloptera karima sp. nov.}

(Figures 69-71)

Material examined. Holotype. Congo, Brazzaville, ORSTOM park, 22. XI.-24. XII. 1963, light trap, leg. J. Balogh, A. Zicsi \& S. Endrődy-
Younga, (1 male, OPC). Paratypes. Same as of holotype (7 males, OPC).

Diagnosis. This new species has the shortest lateral lobes of segment $X$ with blunt apices. The aperture rim of the invaginated distal end of the phallotheca, the entrance atrium and its apical opening with the rim configuration that is the aperture slit is moved anterad, positioned dorsad supplied with an anterior rim smaller than at $A$. felalla sp. nov. The enlarged phallic head is the most developed in the species group, truncated triangular in ventral view. The phallotremal sclerite and endothecal process complex is located posteroventrad.

Etymology. karima, from „,karima” rim, brim or flange in Hungarian, refers to the enlarged posteromesal lobe of the enforced rim of the aperture slit.

\section{Aethaloptera meyi sp. nov.}

(Figures 72-74)

Material examined. Holotype. Namibia, Kavango, Popa Falls, 29. II. 1992, leg. W. Mey (1 male, ZMB). Paratypes. Namibia, Kavango, Popa Falls, 26. II.-2. III. 1992, leg. W. Mey (1 male, $\mathrm{ZMB}$; 1 male, OPC). $7 \mathrm{~km} \mathrm{E}$ of Rundu, $17^{\circ} 56 \mathrm{~S}$ 19²49, E 18.-19. VI. 1993, leg. B. +M. Uhlig (1 male, ZMB; 1 male, OPC).

Diagnosis. This new species has the longest and more slender lateral lobes of segment $\mathrm{X}$. The aperture rim of the invaginated distal end of the phallotheca, the entrance atrium and its apical opening with the rim configuration that is the aperture slit is moved anterad, positioned dorsad however without any anterior rim like at $A$. karima sp. nov. or elevated rim like at A. felalla sp. nov. The enlarged phallic head is the shortest in the species group. The phallotremal sclerite and endothecal process complex is located posteroventrad.

Etymology. We dedicate this new species to Wolfram Mey to remember his research activity on the African caddis flies. 


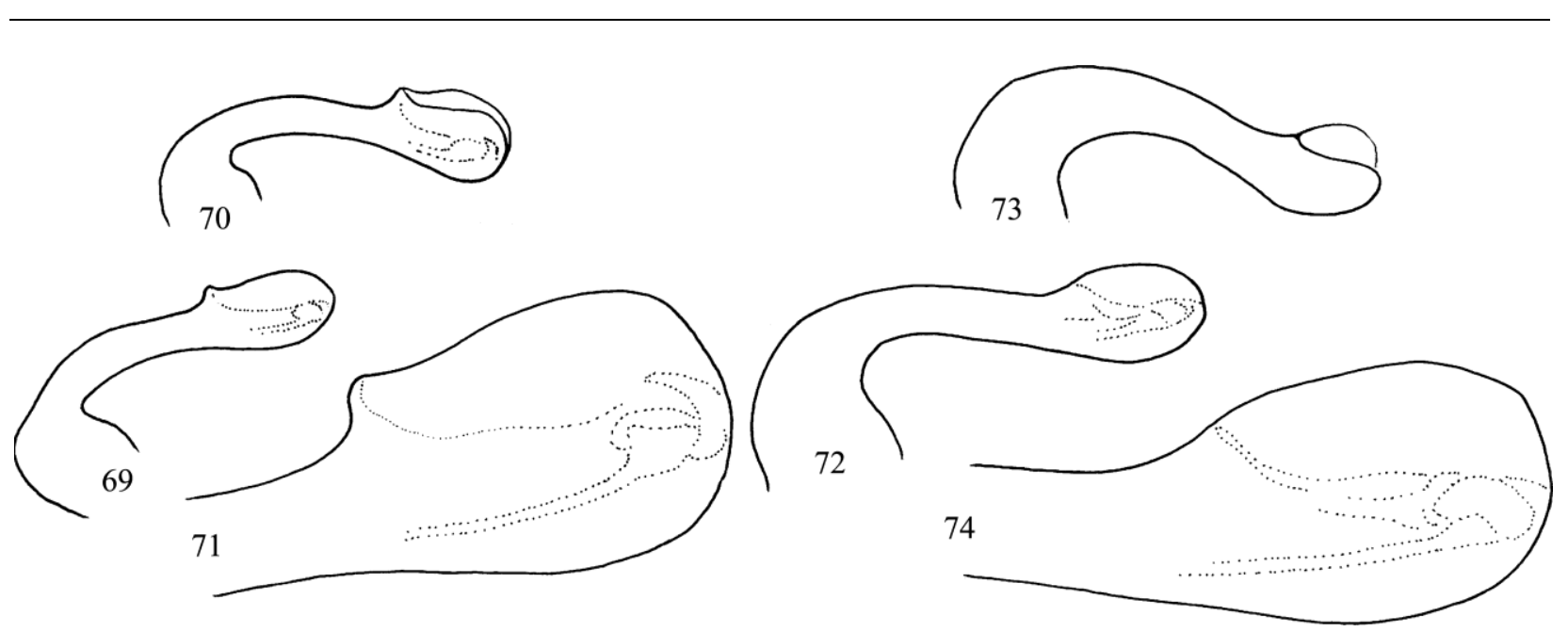

Figures 69-71. Aethaloptera karima sp. nov. $69=$ stereomicroscope lateral profile of the phallic organ, $70=$ stereomicroscope dorsolateral profile of the phallic organ, $71=$ compound microscope lateral profile of the phallic head with internal dotted contours of entrance atrium and phallotremal-endothecal sclerite complex.

Figures 72-74. Aethaloptera meyi sp. nov. $72=$ stereomicroscope lateral profile of the phallic organ, $73=$ stereomicroscope dorsolateral profile of the phallic organ, $74=$ compound microscope lateral profile of the phallic head with internal dotted contours of entrance atrium and phallotremal-endothecal sclerite complex.

\section{REFERENCES}

BANKs, N. (1920): New Neuropteroid insects. Bulletin of the Museum of Comparative Zoology at Harvard College, 64: 299-362. doi: 10.5962/bhl.title.28705

BANKS, N. (1938): Further Neuropteroid insects from Malaya. Journal of the Federated Malay States $\mathrm{Mu}$ seums, 18: 220-235.

BARNARD, K.H. (1934): South African Caddis-flies (Trichoptera). Transactions of the Royal Society of South Africa, 21(4): 291-394. doi: $10.1080 / 00359193409518885$

BARNARD, P.C. (1980): A revision of the Old World Polymorphanisisni (Trichoptera: Hydropsychidae). Bulletin of the British Museum (Natural History), Entomology series, 41(2): 59-106.

BRAUER, F. (1875): Beschreibung neuer und ungenügend bekannter Phryganiden und Oestriden. Verhandlungen der Zoologisch-Botanischen Gesellschaft in Wien 25: 69-78.

KolenATI, F.A. (1859): Genera et species Trichopterorum. Pars altera. Aequipalpidae. Nouveaux Mémoires de la Société Imperiale des Naturalistes de Moscou,11: 141-296.
KORECKI, J. (2006): Revision of the males of the Hydropsyche scalaris group in North America (Trichoptera: Hydropsychidae). Ph. D. Thesis Clemson University, $211 \mathrm{pp}$.

Lestage, J.-A. (1919): Les Trichoptéres d'Afrique. Catalogue synonymique et systématique des Espéces connues. Revue de Zoologie et de Botanique africaines, 6(3): 251-335.

LeStAGE, J.-A. (1936): Notes trichoptérologiques. XIV. Les composantes de la faune sud-africaine et la dispersion transafricaine de quelques espéces. Bulletin et Annales de la Societe Royale Belge d'Entomologie, 76:165-192.

KIMMINS, D.E. (1957): Lectotypes of Trichoptera from the McLachlan collection now in the British Musem (Natural History). Bulletin of the British Museum (Natural History) Entomology, 6(4):91126.

Kimmins, D.E. (1962): New African Caddis-flies (Order Trichoptera). Bulletin of the British Museum (Natural History) Entomology, 12(2): 81-121.

MalicKY, H. (1998): Ein Beitrag zur Kenntnis asiatischer Amphipsyche und Polymorphanisini (Trichoptera, Hydropsychidae). (Gleichzeitig 23. Ar- 
beit über thailandische Köcherfliegen). Stapfia, 55: 399-408.

MARlier G. (1943): Trichopteres du Congo belge. Revue de Zoologie et de Botanique africaines, 37: 64-88.

MARLIER G. (1962): Genera des Trichopteres de l'Afrique. Annales Musee Royal de l'Afrique Centrale Tervuren, Belgique, Serie $8^{\circ}$, Sciences Zoologiques, 109: 1-263.

Martynov, A.B. (1910): The Trichoptera of Siberia and adjacent region. Annuaire du Musée Zoologique de l'Académie Imperiale de Sciences de St.Pétersbourg, 15(4): 351-429.

MARTYNOV, A.B. (1935): On a collection of Trichoptera from the Indian Museum. Records of the Indian Museum, 37: 93-209.

MCLACHLAN, R. (1880): A monographic revision and synopsis of the Trichoptera of the European fauna. Part II. London, 84 pp.

MCSHEA, D.W. \& BRANDON, R. (2010): Biology's first law. University of Chicago Press, Chicago, 184 pp.

MCSHEA, D.W. \& HordiJK, W. (2013): Complexity by subtruction. Evolutionary Biology, 40: 504-520.

NAVAS, L. (1915): Notes sur quelques Névroptéres du Congo belge. Revue Zoologique Africaine, 4(2-3): 172-182.

NAVAS, L. (1916): Neuropteros neuvos o poco conocidas. Memorias de la Real Academia de. Ciencias y Artes Barcelona, 12: 219-243.

OGBOGU, S.S. (2005): First report of Aethaloptera dispar Brauer, 1875 (Trichoptera: Hydropsychidae) from Ile-Ife, southwsetern Nigeria, West Africa. Zootaxa 1088:25-32. doi: 10.11646/zootaxa.1088.1.4

OlÁH, J., ChVojka, T.P., CopPa, G., GodunKo, R.J., LODOVICI, O., MAJECKA, K., MAJECKI, J., SZCZES-
NY, B., URBAnIC, G. \& VAlle, M. (2015): Limnephilid taxa revised by speciation traits: Rhadicoleptus, Isogamus, Melampophylax genera, Chaetopteryx rugulosa, Psilopteryx psorosa species groups, Drusus bolivari, Annitella kosciuszkii species complexes (Trichoptera, Limnephilidae). $O$ puscula Zoologica, Budapest, 46(1): 3-117. doi: 10.18348/opzool.2015.1.3

Oláh, J., BeshKov, S., Chvojka, T.P., Ciubuc, C., COPPA, G., IBRAHIMI, H., KovÁCS, T., MEY, W. \& OLÁH, J. JR. (2017): Revision of Drusinae subfamily (Trichoptera, Limnephilidae): divergence by paraproct and paramere, speciation in isolation by integration. Opuscula Zoologica, Budapest, 48(S1): 3-228. doi: 10.18348/opzool.2017.S1.3

OlÁH, J. \& OlÁH, J. JR. (2017): Fine phenomics applied to the Nectopsyche genus (Trichoptera): species delineation by speciation traits. Opuscula Zoologica, Budapest, 48(2): 117-184. doi: 10.18348/opzool.2017.2.117

OMland, K.E., COOK, L.G. \& CRISP, M.C. (2008): Tree thinking for all biology: the problem with reading phylogenies as ladders of progress. BioEssays 30: 854-867. doi: 10.1002/bies.20794

StATZNER, B. \& GiBON, F.-M. (1984): Keys to adult and immature Macronematinae (Insecta: Trcihoptera) from the Ivory Coast (West Africa) with notes on their taxonomy and distribution. Revue d'Hydrobiologie Tropicale, 17(2): 129-151.

Ulmer, G. (1906): Neuer Beitrage zur Kenntnis aussereuropaeischer Trichopteren. Notes from the Leyden Museum, 28: 1-116.

Ulmer, G. (1907): Trichopteren. Monographie der Macronematinae. Collections Zoologiques $\mathrm{du} \mathrm{Ba-}$ ron Edm. De Selys Longchamps, 6(2): 1-121.

ULMER, G. (1951): Köcherfliegen (Trichopteren) von den Sunda-Inseln (Teil I). Archiv für Hydrobiologie, Supplement, 19:1-528. 